\title{
AVALIAÇÃO AMBIENTAL DA BACIA HIDROGRÁFICA CÓRREGO DA ONÇA GUARAÇAI - SP
}

Cristhy Willy da Silva Romero ${ }^{1}$

Fabrício Lopes de Macedo ${ }^{2}$

Hélio Ricardo Silva ${ }^{3}$

RESUMO: O município de Guaraçaí localizado na região noroeste do estado de São Paulo apresenta relevo predominantemente suave-ondulado tendo sua área distribuída entre as bacias hidrográficas do Rio Tietê e do Rio Aguapeí. O objetivo principal deste trabalho foi realizar uma avaliação ambiental da Área de Preservação Permanente (APP) da microbacia Córrego da Onça. Foram utilizadas técnicas de geoprocessamento para delimitação dos divisores de água das sub-bacias hidrográficas, vetorização da rede de drenagem e avaliação do nível de degradação das Áreas de Preservação Permanentes. Além disso foram utilizadas técnicas de georreferenciamento para o refinamento do registro das imagens fusionadas e para verificação dos dados obtidos em campo. A Microbacia do Córrego da Onça foi classificada de acordo com Strahler (1957) como sendo de $3^{\mathrm{a}}$ ordem também foi caracterizada como "parcialmente sujeita a enchentes" segundo Oliveira (1997).

\footnotetext{
${ }^{1}$ Mestrando do Curso de Agronomia, Faculdade de Engenharia, Campus de Ilha Solteira (UNESP). E-mail: crwilly@hotmail.com

${ }^{2}$ Doutorando do Curso de Agronomia, Faculdade de Engenharia, Campus de llha Solteira (UNESP). Email: fabriciolmacedo@hotmail.com

${ }^{3}$ Docente do Departamento de Fitossanidade, Engenharia Rural e Solos da Faculdade de Engenharia de Ilha Solteira (UNESP). E-mail: hrsilva@agr.feis.unesp.br
} 


\section{INTRODUÇÃO}

A bacia hidrográfica é uma unidade geomorfológica fundamental da superfície terrestre, considerada como principal unidade fisiográfica do terreno, porque suas características governam, no seu interior, todo o fluxo superficial da água. Constitui, portanto, uma área ideal para o planejamento integrado do manejo dos recursos naturais no meio ambiente por ela definido.

A noção de bacia obriga, naturalmente, a existência de divisores d'água, cabeceiras ou nascentes, cursos d'água principais, afluentes, subafluentes, bem como, uma hierarquização dos canais escoadouros e uma distribuição dos solos predominantes (TUCCI, 2004). A degradação ambiental de bacias hidrográficas tem sido um assunto muito estudado, pois, mesmo com grandes movimentações politicas sobre o assunto a incidência de bacias e microbacias com alto nivel de degradação é alto.

São necessárias tecnologias para essas identificações de degradação. Um método bastante comum é o de Geoprocessamento que segundo SILVA (1997) pode ser definido como um conjunto de procedimentos que, operando sobre bases de dados georreferenciados existentes e originados do sensoriamento remoto, da cartografia digital ou de qualquer outra fonte, executa classificações e outras transformações dirigidas à elucidação da organização do espaço geográfico.

Sensoriamento Remoto consiste na utilização conjunta de modernos instrumentos (sensores), equipamentos para processamento e transmissão de dados e plataformas (aéreas ou espaciais) para carregar tais instrumentos e equipamentos, com o objetivo de estudar o ambiente terrestre através do registro e da análise das interações entre a radiação eletromagnética e as substâncias componentes do planeta Terra, em suas mais diversas manifestações (NOVO, 1989).

\section{REVISÃO BIBLIOGRÁFICA}

\subsection{Sensoriamento Remoto}


O Sensoriamento Remoto pode ser considerado como uma ciência onde pode se obter informações sobre determinado alvo, área ou fenômeno, por meio de análise de dados coletados por sensores (GARCIA, 1982)

Para MORAES (1999) pode-se entender $r$ sensoriamento remoto, como formas de obtenção de dados sobre um objeto, terreno, espécime, etc, sem contato físico com o mesmo.

Já segundo FLORENZANO (2002), sensoriamento remoto é a tecnologia que permite obter imagens e outros tipos de dados da superfície terrestre, através da captação e do registro da energia refletida ou emitida pela superfície. $O$ termo sensoriamento refere-se à obtenção dos dados, e remoto, que significa distante, é utilizado porque a obtenção é feita à distância, ou seja, sem o contato físico entre o sensor e a superfície terrestre.

Segundo Crosta (1992), as imagens de Sensoriamento Remoto vêm servindo de fontes de dados para estudos e levantamentos de diversas áreas como as geológicas, ambientais, agrícolas, cartográficas, florestais e oceanográficas entre outras.

\subsection{Geoprocessamento}

Geoprocessamento é um conjunto de conceitos, métodos e técnicas que, atuando sobre bases de dados georreferenciados, por computação eletrônica, propicia a geração de análises e sinteses que consideram conjugadamente, as propriedades intrinsicas e geotopológicas dos eventos e entidades identificados, criando informação relevante para apoio à decisão quanto aos recursos ambientais (SILVA, 2009).

Já segundo MOREIRA (2011), o geoprocessamento pode ser entendido como sendo a utilização de técnicas matemáticas e computacionais para tratar dados de objetos ou fenômenos geograficamente identificados ou extrair informações desses objetos ou fenômenos, quando eles são observados por um sistema sensor.

\subsection{Redes de Drenagem}




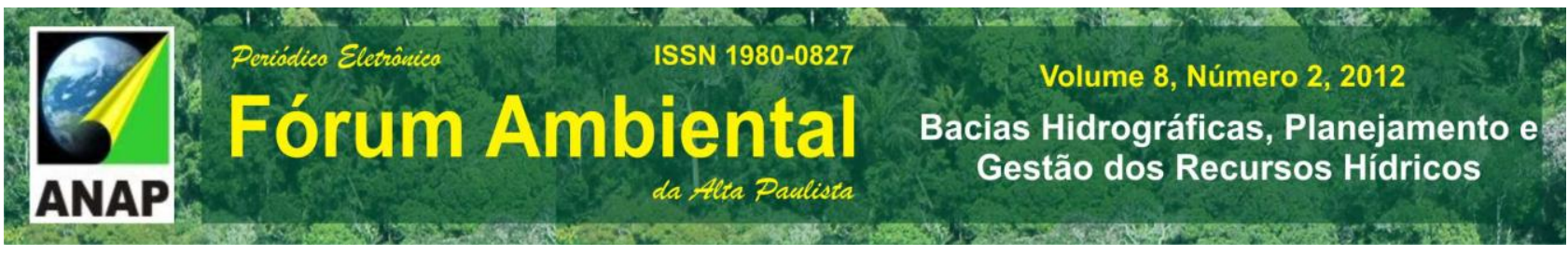

A rede de drenagem de uma região geográfica define os caminhos de escoamento de líquidos, normalmente água de chuva, de acordo com o relevo da região. A informação por ela gerada é usada em atividades diversas, tais como: estudo de relevo, determinação de áreas com risco de erosão do solo, transporte de poluentes, delimitação de áreas inundadas e estudo de bacias hidrográficas. (ROSIM \& PELLEGRINO, 1999). O deflúvio de uma bacia hidrográfica resulta de fluxos líquidos superficiais e subsuperficiais (RESENDE et al., 1995).

Com o crescente uso da água para diversos fins, e o estado de degradação em que se encontram os mananciais, é necessário administrar sua disponibilidade e uso, além do conhecimento atualizado do quadro degradante quando houver e criar processos de gerenciamento para sua recuperação e/ou conservação, assegurando desta maneira a qualidade e quantidade dos recursos que esta pode oferecer (BORSATO, 2004).

De acordo com PINTO (2003), nascentes são pontos iniciais dos cursos d'água formadores dos pequenos e grandes rios. Também são conhecidas como minas, fio d'água, olho d'água e fontes, sendo caracterizadas como os pontos nos quais a água subterrânea aflora naturalmente através da superfície do solo, mesmo que de forma intermitente

\section{4. Áreas de Preservação Permanente}

A atividade agricola é uma das principais atividades econômicas responsáveis pelas mudanças do padrão do uso de cobertura do solo, sendo que esta, realizada de forma não sustentável, é uma das principais responsáveis pelos diversos danos ambientais que afetam a sociedade (TURETTA et al. 2010)

Segundo Francisco (2006) as Áreas de Persevação Permanente (APP) são áreas com função ambiental de preservar recursos hídricos, a paisagem, a biodiversidade, 0 fluxo gênico e flora, proteger o solo e assegurar o bem-estar das populações humanas. Portanto são delimitadas e protegidas pelo Código Florestal e estão localizadas em faixas marginais de cursos d'águas, tanques, represas, lagos naturais, nascentes, e topo de morros entre outras. 


\section{MATERIAL E MÉTODOS}

\subsection{Caracterização da Área de Estudo.}

O município de Guaraçaí localiza-se na região noroeste do Estado de São Paulo na província geomorfológica do Planalto Ocidental Paulista. Integrante da região administrativa de Araçatuba, com uma extensão territorial de $568 \mathrm{~km}^{2}$. Guaraçaí limita-se ao norte com o rio Tietê e ao Sul com o rio Aguapeí, integrando duas importantes Unidades de Gerenciamento de Recursos Hídricos do oeste paulista: Bacia Hidrográfica do Baixo Tietê e Bacia Hidrográfica do rio Aguapeí. A microbacia hidrográfica Córrego da Onça, esta localizada na porção sul do município possuindo uma área de 40,29 $\mathrm{km}^{2}$ sendo ocupada predominantemente pela cultura da cana de açúcar.

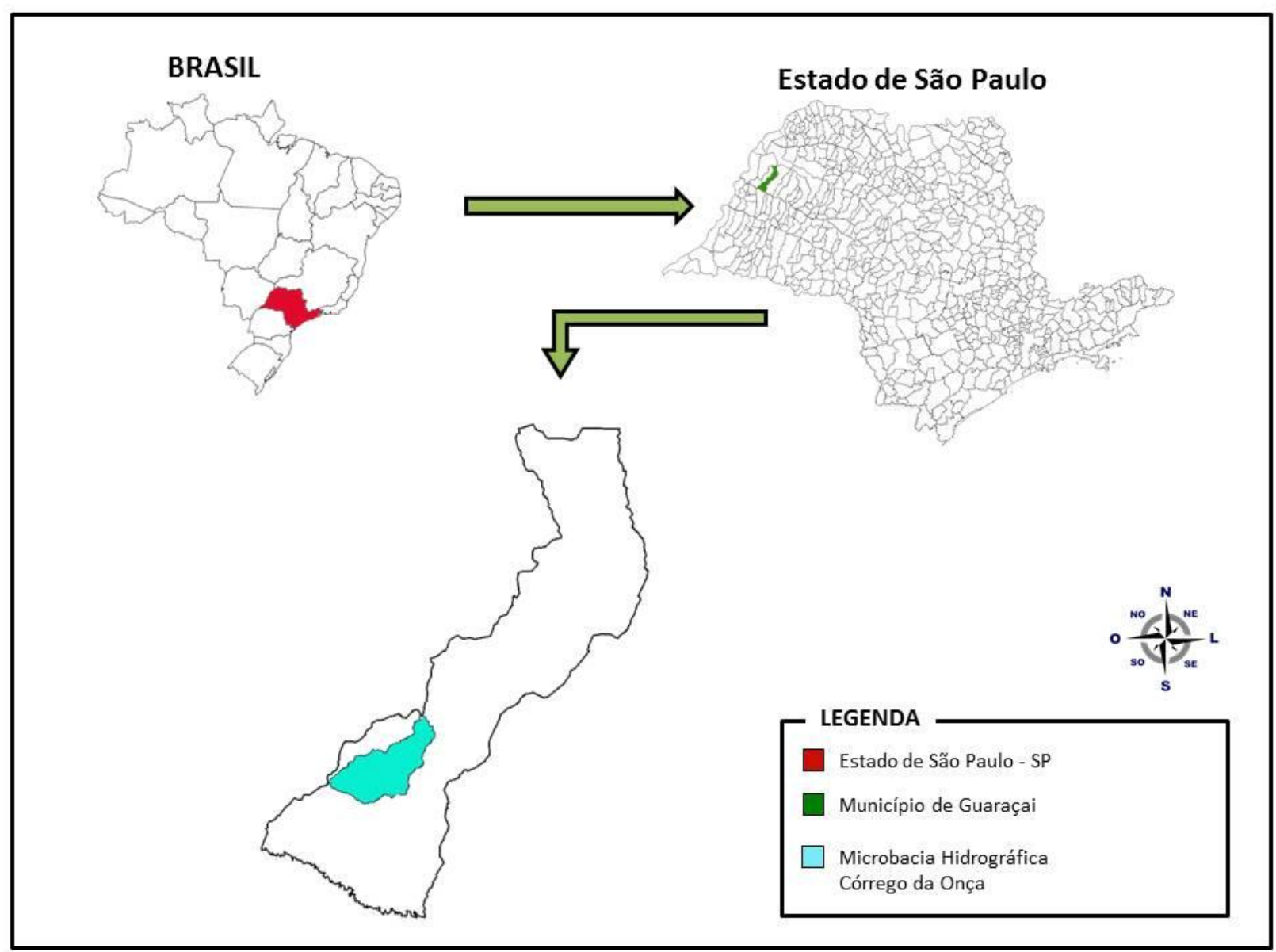

Figura 1. Localização da área de estudo microbacia 


\subsection{Metodologia}

Foi obtida a imagem ortorretificada do LANDSAT 7, sensor ETM+, órbita/ponto 222/75 do dia 28 de abril de 2006 disponibilizada no site do Global Land Coveracility(http://glcf.umiacs.umd.edu/data/landsat/). Esta imagem foi utilizada para o georreferenciamento da imagem atualizada do satélite CBERS-2B, sensores CCD e HRC que cobre a microbacia hidrográfica.

Foi utilizada a imagem orbital do satélite CBERS-2B, sensor CCD com resolução espacial de 20 metros e sensor HRC com resolução de 2,5 metros, obtidas através do site do Instituto Nacional de Pesquisas Espaciais - INPE (http://www.inpe.br) acessado no dia 13 de julho de 2010. A imagem orbital da câmera de média resolução, CCD, utilizada foi a orbitas/pontos 159/124 do dia 27/09/2009. Em relação às imagens de alta resolução do sensor HRC, também disponibilizadas no mesmo site do INPE, foram obtidas quatro imagens das seguintes orbitas/pontos: 159_A/124_1 do dia 27 de setembro de 2009, 159_A/124_2 do dia 27 de setembro de 2009, 159_B/124_1 do dia 05 de outubro de 2009, 159_A/124_5 do dia 27 de setembro de 2009. Para o desenvolvimento do trabalho foi utilizado o software de domínio público SPRING (Sistema de Informações Georreferenciadas) na versão 5.2.1, desenvolvido pelo INPE. Inicialmente foi criado o Banco de Dados denominado Córrego Onça, dentro deste Banco de Dados foi criado o projeto também denominado Córrego Onça. Foi adotada a projeção Universal Transverse Mercator (UTM) e datum de referência SIRGAS2000. O passo seguinte foi a importação da imagem ortorretificada do satélite LANDSAT para o projeto Córrego Onça.

$\mathrm{Na}$ etapa seguinte, foi realizada a operação de registro da imagem CCD/CBERS tomando como referência a imagem LANDSAT 7/ETM+ ortorretificada. Em seguida foi realizada a técnica de restauração da imagem CCD/CBERS. Posteriormente utilizando como referência a imagem CCD/CBERS foi efetuado o registro das imagens CBERS, sensor HRC. Como cada imagem do sensor HRC cobre uma área 1/25 da imagem CCD, inicialmente foi realizado o processo denominado Reamostragem.

Após essa etapa foi utilizada a técnicas de fusão Intensidade-Matiz-Saturação (IHS). Após essa etapa foi gerado o mosaico das imagens HRC fusionadas. Finalmente 


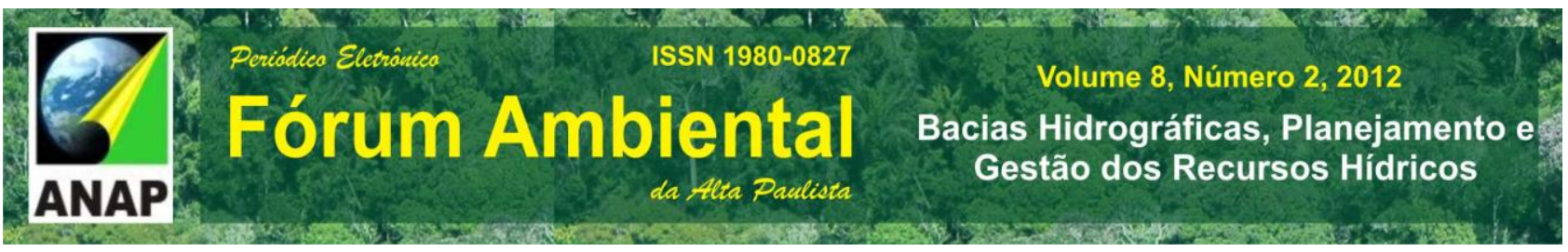

foi realizado um refinamento no georreferenciamento dessas imagens utilizando 30 pontos de controle coletados em campo através de um conjunto GPS Geodésico modelo SYSTEM 1200 - RTK da marca LEICA. Esta etapa teve como finalidade a conferência de pontos de apoio (georreferenciados) para fornecer controle às imagens orbitais usadas no projeto. A metodologia utilizada seguiu as normas técnicas oficiais vigentes NBR/ABNT 13.133/94, LEI 10267/INCRA.

$\mathrm{Na}$ etapa seguinte foi realizada a vetorização da rede de drenagem e do divisor de água da microbacia. Após a identificação dos canais de drenagem, foi utilizada a ferramenta Edição Vetorial para traçar as linhas que representam os seguintes dados da rede de drenagem: leito seco e canal perene. Em seguida foram identificadas e digitalizadas as nascentes.

Nas regiões da microbacia onde os canais de drenagem eram muito estreitos e não possuíam áreas úmidas, a rede de drenagem foi digitalizada através do Método das Crênulas (BIASI, 1970) que utiliza as inflexões das curvas de nível presentes nas cartas do IGGSP registradas e com o auxílio das imagens de alta resolução espacial disponíveis no Google Earth.

$\mathrm{Na}$ etapa seguinte foi realizada a hierarquização de toda a rede de drenagem da microbacia hidrográfica, utilizando o método proposto por Strahler (1964). A avaliação da acurácia do divisor de água foi realizada através de coleta de pontos obtidos em campo com GPS geodésico e a das nascentes foi verificada através de trabalhos de campo em 5 das nascentes distribuídas aleatoriamente, correspondente a uma amostra representativa do total de 52 nascentes existentes na bacia hidrográfica.

O processo de caracterização fisiográfica consiste na determinação de uma série de fatores como: área de drenagem, fator de forma, coeficiente de compacidade, sistema de drenagem, ordem dos canais, densidade de drenagem, extensão média do escoamento superficial. Moura (2008) afirma que o processo de caracterização fisiográfica em bacias é essencial para a elaboração e implementação de futuros projetos, pois, os resultados auxiliam na compreensão do escoamento superficial de uma bacia hidrográfica. O fator área de drenagem segundo Andrade et al. (2008) compreende à medida em projeção horizontal, em que, é considerada toda a área da bacia hidrográfica. Normalmente seus resultados são expressos em $\mathrm{km}^{2}$. 
Para a determinação do formato da bacia, é necessária a obtenção de dois outros fatores: Coeficiente de compacidade (Kc), esse fator relaciona o perímetro de uma bacia e a circunferência de área igual presente na respectiva bacia, quanto mais irregular a forma da bacia hidrográfica, maior será esse índice (Carvalho et al., 2009). Seu cálculo utiliza a seguinte expressão:

$$
K c=0,28 \cdot \frac{p}{\sqrt{A}}
$$

Onde: $\mathrm{Kc}=$ coeficiente de compacidade (adimensional); $\mathrm{P}=$ perímetro $(\mathrm{km}) ; \mathrm{A}=$ área $(\mathrm{km} 2)$; O Fator Forma (Kf) é determinado através da razão entre a largura média da bacia e o comprimento axial da mesma. Andrade et al. (2008) complementam que esse fator é obtido com a medição do comprimento desde a desembocadura até a cabeceira da bacia. $O$ cálculo desse fator é determinado pela equação:

$$
F=\frac{A}{L^{2}}
$$

Onde: $F=$ Fator de Forma (adimensional); $A=$ Área $\left(\mathrm{km}^{2}\right) ; \mathrm{L}=$ Comprimento do eixo principal $(\mathrm{km})$; Indice de circularidade (Ic) esse índice possui uma variação de acordo com o formato da bacia. Tende para unidade em bacias circulares e diminui em bacias com formatos alongados. Segundo Andrade et al. (2008), esse índice relaciona 0 perímetro da bacia e a sua área. A determinação desse fator utiliza a seguinte equação:

$$
I c=\frac{12,57 \cdot A}{p^{2}}
$$

Onde: $\mathrm{Ic}=$ índice de circularidade (admensional); $\mathrm{A}=$ área de drenagem $\left(\mathrm{m}^{2}\right) ; \mathrm{P}=$ perímetro (m); O parâmetro sistema de drenagem é composto pelo rio principal de uma bacia hidrográfica e por seus tributários.

A determinação referente ao sistema de drenagem possibilita a deliberação sobre o maior ou menor tempo que a água demora a deixar uma bacia hidrográfica. Alguns parâmetros são fundamentais no estudo do sistema de drenagem: Ordem dos Canais, Densidade de Drenagem e Extensão média do Escoamento Superficial; O parâmetro ordem dos canais se refere a uma classificação sobre o grau de ramificações e/ou bifurcações presentes em uma bacia hidrográfica. A classificação de ordenamento dos cursos mais utilizada é a proposta por Horton (1945) e modificada por Strahler (1957); Segundo Carvalho et al. (2009), a densidade de drenagem indica a real eficiência da drenagem atuante na bacia hidrográfica. Sua determinação consiste numa relação entre o 
comprimento total dos cursos d'água e a área de drenagem. O parâmetro é obtido através da equação:

$$
D d=\frac{R d}{A}
$$

Onde: $\mathrm{Dd}=$ é a densidade de drenagem $\left(\mathrm{km} / \mathrm{km}^{2}\right) ; \mathrm{Rd}=$ rede de drenagem $(\mathrm{km})$; $\mathrm{A}=$ é a área da bacia $\left(\mathrm{km}^{2}\right)$; Extensão média do escoamento superficial esse parâmetro relaciona a distância média que a água proveniente das precipitações, teria que escoar sobre a bacia em linha reta do ponto onde ocorreu a sua queda até o ponto mais próximo do leito de qualquer curso d'água. Para facilitar a obtenção do parâmetro, a bacia é modificada para forma de retângulo com uma mesma área, no qual, o lado maior é a soma dos comprimentos da bacia (Vilella \& Mattos, 1975). Sua obtenção é ocasionada através da equação:

$$
l=\frac{A}{4 \cdot L}
$$

Onde: $A=$ área $\left(\mathrm{km}^{2}\right) ; \mathrm{L}=$ Comprimento do rio principal $(\mathrm{km})$.

\section{RESULTADOS E DISCUSSÕES}

Os resultados referentes às características fisiográficas da Microbacia do Córrego da Onça (Tabela 1), evidenciam que, a área de estudo pode ser classificada como "parcialmente sujeita a enchentes" visto que, o Kc obtido foi de 1,44. Essa classificação de bacias hidrográficas foi realizada por Oliveira (1997), em que, valores de Kc <1,2 (totalmente sujeito a enchente), valores de Kc entre 1,2 a 1,5 (parcialmente sujeito a enchentes) e Kc > 1,5 (não sujeito a enchentes). Utilizando ainda esse parâmetro foi possível concluir que a microbacia não tende a forma circular, pois, o valor determinado esta distante da unidade. Villela \& Matos (1975) asseguram que bacias que apresentam formatos alongados, são pouco propensas a enchentes, já que, apresentam menores concentrações de deflúvio. 
Tabela 1. Parâmetros fisiográficos determinados para a Microbacia do Córrego da Onça

\begin{tabular}{ll}
\hline Parâmetro & Dimensões \\
\hline Área de drenagem & $40,3 \mathrm{~km}^{2}$ \\
Perímetro & $32,7 \mathrm{~km}$ \\
Comprimento do rio principal & $11,46 \mathrm{~km}$ \\
Coeficiente de compacidade (Kc) & 1,44 \\
Fator forma (Kf) & 0,28 \\
Índice de circularidade (Ic) & 0,47 \\
Ordem dos canais & $3^{\mathrm{a}}$ ordem \\
Densidade de drenagem & $1,64 \mathrm{~km} / \mathrm{km}^{2}$ \\
\hline
\end{tabular}

De maneira análoga ao Kc, o Kf também faz referência a suscetibilidade de enchentes. O valor do $\mathrm{Kf}$ adquirido para a área de estudo foi de 0,28 . Segundo Wisler \& Brater (1964) valores baixos para esse parâmetro, evidenciam que as bacias hidrográficas são pouco propensas aos processos de inundações quando confrontadas com bacias do mesmo tamanho, que apresentem um Kf mais elevado.

O valor de lc obtido para a área de estudo foi de 0,47 , demonstrando que a microbacia não apresenta dificuldades com o escoamento superficial da chuva, devido ao seu formato que tende a ser mais alongado. Muller (1953) e Schumm (1956) rotulam o Ic de três formas: valores $<0,51$ demonstram que a bacia tende a ser mais alongada e tem como tendência o favorecimento do escoamento; $=0,51$ demonstra um nível moderado de escoamento e valores $>0,51$ apresentam forte indício de que a bacia tende a um formato circular, o que favorece os processos de enchentes. A densidade de drenagem obtida foi de $1,87 \mathrm{~km} / \mathrm{km}^{2}$, sendo considerada como baixa de acordo com a classificação de Christofoletti (1969), visto que, o valor determinado foi inferior $a<7,5 \mathrm{~km} / \mathrm{km}^{2}$.

O baixo valor para esse parâmetro segundo Christofoletti (1980) classifica essa microbacia como sendo pouco suscetível a processos erosivos naturais. Carvalho et al. (2009) afirmam que, a obtenção de baixos valores para a densidade de drenagem, estão 
geralmente relacionados com regiões de rochas permeáveis e de regime pluviométrico com chuvas de baixa intensidade.

A ordem dos canais corresponde ao grau de ramificação ou bifurcação presente em uma bacia. A Microbacia do Córrego da Onça foi classificada de acordo com Strahler (1957) como sendo de $3^{a}$ ordem. Esse resultado indica que a área de estudo apresenta um o sistema de drenagem pouco ramificado. Tonello et al. (2006), afirmam que, para o número abaixo de 4 o valor é considerado trivial em pequenas bacias, e que, quanto mais elevado o índice obtido para esse fator, maior será a rede de drenagem de uma bacia.

A Análise da Tabela 2, permite verificar que a microbacia hidrográfica Córrego da Onça compreende uma área de 176,58 ha composta de área de preservação permanente, onde 136,7 há se encontra em estado de parcial degradação e 37,2 ha está em estado de completa degradação, restando apenas 2,68 ha de área com vegetação conservada, onde também é possível a constatação do estado parcialmente degradado ou totalmente degradado em todas as nascentes contidas na microbacia.

Tabela 2. Níveis de degradação da Microbracia do Córrego da Onça.

\begin{tabular}{ll}
\hline Parâmetro & Dimensões \\
\hline Vegetação conservada & 2,68 ha \\
Vegetação parcialmente degradada & 136,70 ha \\
Vegetação degradada & 37,20 ha \\
\hline
\end{tabular}

Esta informação pode ser também visualizada pela figura 2. 


\section{AVALIAÇÃO AMBIENTAL DAS ÁREAS DE PRESERVAÇÃO PERMANENTE DA MICROBACIA CÓRREGO DA ONÇA, GUARAÇAI(SP)}
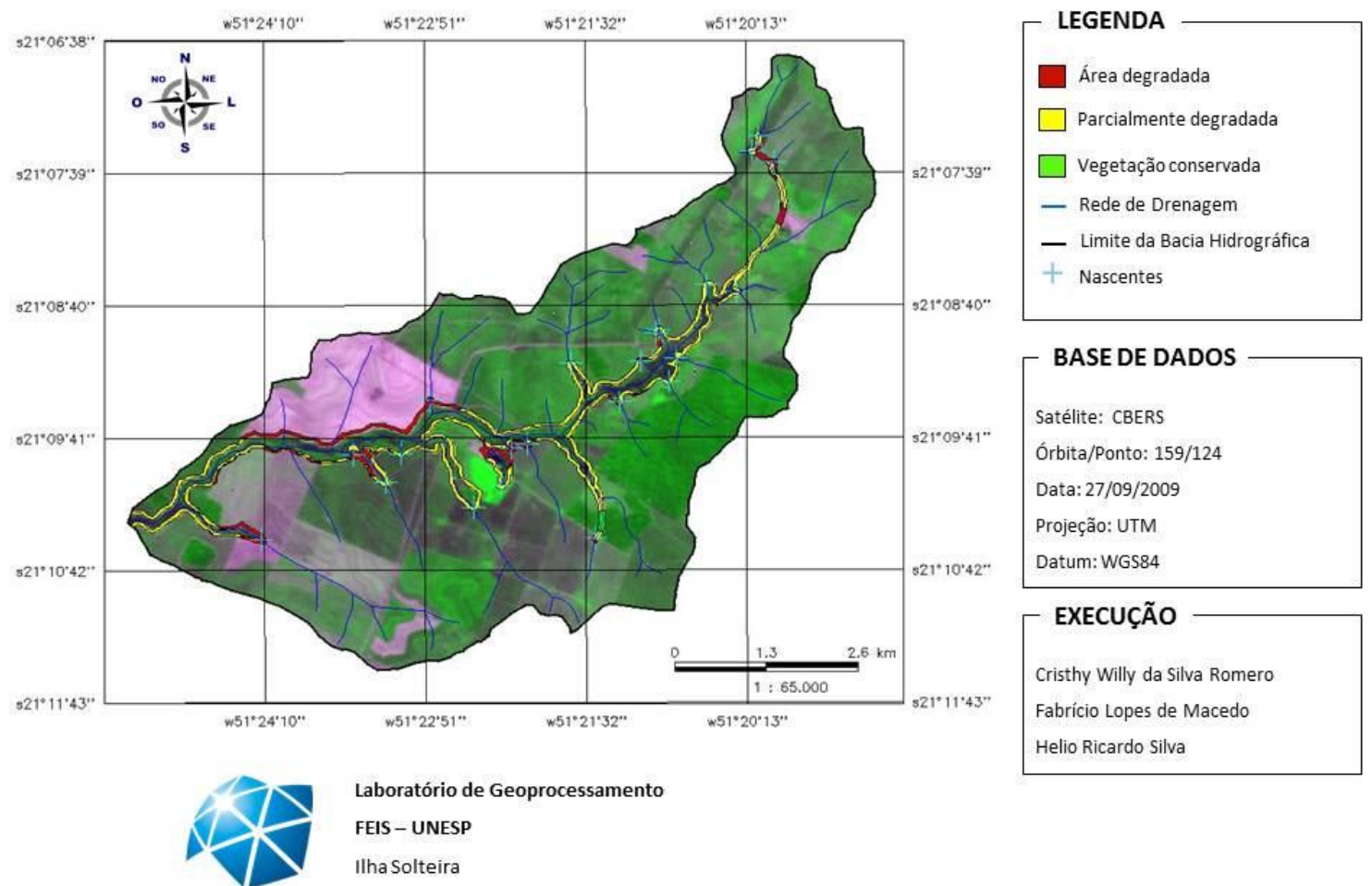

- EXECUÇão

Cristhy Willy da Silva Romero

Fabrício Lopes de Macedo

Helio Ricardo Silva

Figura 2. Delimitação de áreas de preservação permanente (APP) e níveis de degradação.

\section{CONCLUSÕES}

Com o uso de Sistema de Informação Geográfica, foi possível fazer uma análise completa do nível de degradação da área de preservação permanente (APP) da Microbacia Córrego da Onça, sendo possível a análise fisiográfica da mesma, obtendo-se os resultados de $\mathrm{Kc}, \mathrm{Kf}$, Ic, extensão da bacia e suas ramificações, tornando possível sua caracterização.

A forma alongada da bacia hidrográfica e o coeficiente de compacidade permite concluir que a área de estudo possui pouca propensão a enchente e condição favorável 
ao escoamento. Portanto, conclui-se que o alto nível de degradação está relacionado a ações antrópicas, ocorrendo mal uso e manejo do solo.

\section{REFERÊNCIAS}

ANDRADE, N.L.R. de; XAVIER, F.V.; ALVES, E.C.R. de F. SILVEIRA, A.; OLIVEIRA, C.U.R. de. 2008. Caracterização morfométrica e pluviométrica da bacia do Rio Manso MT. Revista Brasileira de Geociências, 27, 2, 237-248.

BIASI, M. Carta de declividade de vertentes: confecção e utilização. Geomorfologia. São Paulo. 21-8-12, 1970.

BORSATO, F. H. \& MARTONI, A. M. Estudo da fisiografia das bacias hidrográficas urbanas no Município de Maringá, Estado do Paraná. Acta Scientiarum. Human and Social Sciences. Maringá, v. 26, n. 2, p. 273-285, 2004.

CÂMARA, G.; MEDEIROS, J. S. Monitoramento da ocupação agrícola. In: Assad, E . D.; Sano, E. E. Sistemas de informação geográfica: Aplicações na agricultura. 2 ed. Brasília. Embrapa - CPAC, 1998, Cap. 1, p. 3-11.

Carvalho, W.M. de C.; Vieira, E. de O.; Rocha, J.M.J.; Pereira, A.K. dos S.; CARMO, T.V.B. 2009. Caracterização Fisiográfica da Bacia Hidrográfica do Córrego do Malheiro, no município de Sabará - MG. Revista Irriga, 14, 3, 398-412.

CHRISTOFOLETT, A. Geomorfologia. São Paulo: Editora Edgard Blücher / EDUSP, 1980. $150 \mathrm{p}$.

CHRISTOFOLETT, A. Análise morfométrica de bacias hidrográficas. Notícia Geomorfológica. v.18, n. 9, p. 35-64. 1969. 
CROSTA, A.P. Processamentodigital de imagens de sensoriamento remoto. Campinas: Unicamp, 1992. 170p.

FLORENZANO, T. G. Imagens de satélite para estudos ambientais. São Paulo: Oficina de Textos. 2002.

FRANCISCO, C.E.F. Áreas de preservação permante na bacia do ribeirão das anhumas: Estabelecimento de prioridades para recuperação por meio de análise multicriterial. 2006, 108p. Campinas, Dissertação ( Mestado em Agricultura Tropical e Subtropical), Instituto Agronomico. 2006.

HORTON, R.E. 1945. Erosional development of streams and their drainage basins: hidrophysical approach to quantitative morphology. Bulletim Geologic Society of America, v.56, n. 3, p. 275-370.

MORAES, R. M. Sensoriamento remoto e classificação de Imagens: apostila/1999.

MOREIRA, M.A. Fundamentos dos sensoriamento remoto e metodologias de aplicação. Viçosa, MG: Editora da UFV, 2011. 422p.

MOURA, R.S. Caracterização Fisiográfica e Regionalização de Vazão na Microbacia do Córrego do Boi, Aparecida D'Oeste, SP. 2008. Monografia (Engenharia Agronômica). Faculdade de Engenharia do Campus de Ilha Solteira -UNESP. Ilha Solteira - SP, 48p.

MÜLLER, V.C. A quantitative geomorphology study of drainage basin characteristic in the Clinch Mountain Area. New York: Virginia and Tennesse. Dept. of Geology. n. 3, p. 30, 1953.

NOVO, E., 1989. Sensoriamento remote, princípios e aplicações. : Edgard Blucher, São Paulo, 308 páginas.

OLIVEIRA, C.U.R. de. 2008. Caracterização morfométrica e pluviométrica da bacia do Rio Manso - MT. Revista Brasileira de Geociências, 27, 2, 237-248.

PINTO, L.V.A.; BOTELHO, S.A.; DAVIDE, A.C.; FERREIRA, E. Estudo das nasccentes da bacia hidrográfica do Ribeirão Santa Cruz, Lavras-MG. Scientia forestalis, n.65 p.197-206, jun./2004.

RESENDE, M.; CURI, N.; REZENDE, S. B.; CORRÊA, G. F. Pedologia: base para distinção de ambientes. Viçosa: NEPUT, 304p. 1995. 
ROSIM, S.; PELLEGRINO, S. Extração de rede de drenagem de imagem de radar usando modelos digitais de terreno. GIS Brasil 99; 1999; 1; 1; 352; 358.

SILVA, J. X. Metodologia de Geoprocessamento. In: Revista de Pós graduação em Geografa, vol1. Rio de Janeiro: UFRJ/PPGG, P.25-34. 1997.

SILVA, J. X. O que é geoprocessamento?. Revista do CREA-RJ, Rio de Janeiro, n.79, p.42-44, out./nov. 2009.

SCHUMM, S. A. Evolution of drainage systems and slopes in badlands of Perth Amboy. Geological Society of America Bulletin, n. 67, p. 597-646, 1956.

STRAHLER, A. N. 1957. Quantitative analysis of watershed geomorphology. Transaction of America Geophysics Union, v. 38. p 913-920. 1957.

STRAHLER, A.N. (1964) Quantitative geomorphology of drainage basins and channel networks. In: CHOW, Ven Te (Ed.). Handbook of applied Hidrology. New York: McGraw-Hill, p. 4.39-4.76.

TONELlO, K. C.; DIAS, H. C. T.; SOUZA, A. L.; ALVARES, C. A.; RIBEIRO, S.; LEITE, F. P. Morfometria da Bacia Hidrográfica da Cachoeira das Pombas, Guanhães - MG. Revista Árvore, v.30, n.5, p.849-857, 2006.

TUCCI, C. E. M. Controle de enchentes. In. TUCCI,C. E. M. (Org.) Hidrologia: ciência e aplicação.2.ed. Porto Alegre: UFRGS/ABRH, 2000. p.651-658.VILELLA, S. M.; MATOS, A. Hidrologia Aplicada. São Paulo: Editora McGraw-Hill, 1975. 245p

TURETTA, A. P. D. ; PRADO, R. B. . Manejo e Conservaçao do Solo e da Águas no Contexto das Mudanças Ambientais. 01 ed. Rio de Janeiro: Rio de Janeiro, 2010, v.01, p.239-254.

VILELLA, S. M.; MATOS, A. Hidrologia Aplicada. São Paulo: Editora McGraw-Hill, 1975. $245 p$.

WISLER, C. O.; BRATER, E. F. Hidrologia. Tradução e publicação de Missão NorteAmericana pela Cooperação Econômica e Técnica no Brasil. Rio de Janeiro: Ao Livro Técnico S.A. 1964. 484p. 